\title{
Embryology and development of the enteric nervous system
}

\author{
H M Young, C J Hearn, D F Newgreen
}

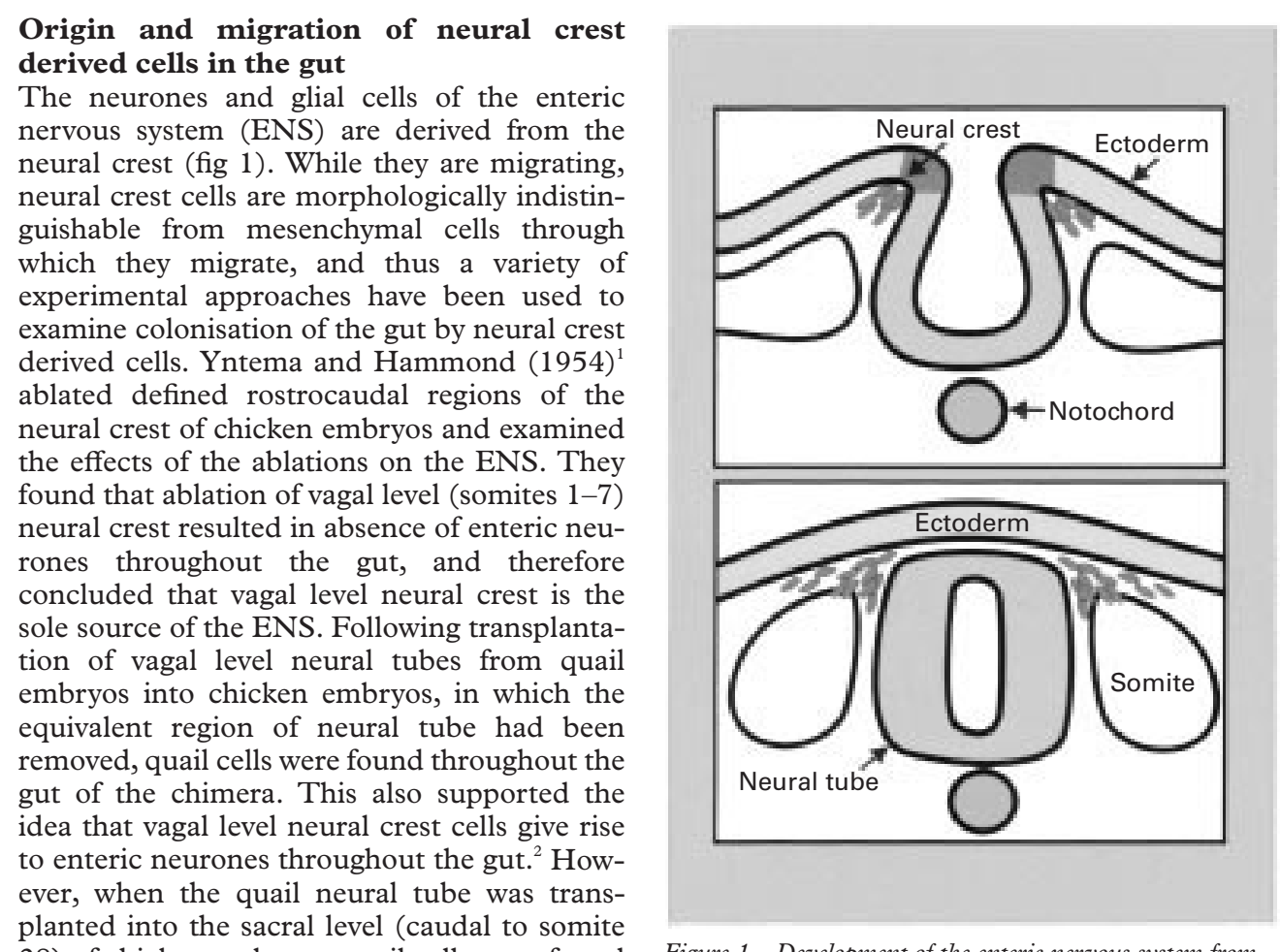
28) of chicken embryos, quail cells were found within the myenteric plexus of the hindgut of the chimeras, indicating that sacral level neural crest cells also contribute to the ENS in the hindgut. ${ }^{2}$ Since then, the contribution of sacral level neural crest to the ENS in the hindgut has been controversial. Studies in which explants of chicken gut were removed and grown on the chorioallantoic membrane of host embryos, ${ }^{3}$ or in which the midgut of chicken embryos was transected prior to the arrival of vagal neural crest cells, ${ }^{4}$ suggested that either the vagal neural crest cells are the sole source of enteric neurones throughout the gut or that sacral level neural crest cells do not give rise to enteric neurones in the hindgut unless the vagal level neural crest cells are present. In contrast, studies in which pre-migratory cells had been labelled with a lipophilic dye or retroviruses have shown that some cells that populate the hindgut arise from sacral level neural crest, and these cells colonise the hindgut well before the arrival of vagal level neural crest cells. ${ }^{56}$

While they are migrating through the gut, neural crest derived cells do not express a neuronal or glial cell phenotype. Recently, a number of markers of neural crest derived cells within the mouse gut have been identified, and thus colonisation of the mouse gut by neural crest cells can be observed directly. These markers include the transgene $D B H$-nlac $Z,{ }^{7}$ receptors for neurotrophic factors including $\mathrm{p} 75,{ }^{8} \mathrm{RET},{ }^{10}$
Figure 1 Development of the enteric nervous system from the neural crest.

GFR $\alpha 1,{ }^{11}{ }^{12}$ and endothelin receptor $\mathrm{B},{ }^{13}$ and the transcription factors MASH $1,{ }^{14}$ Phox $2 \mathrm{a},{ }^{15}$ Phox $2 b,{ }^{16}$ and SOX $10 .{ }^{17}{ }^{18}$ We have examined colonisation of the embryonic mouse gut using antibodies to Phox $2 \mathrm{~b}, \mathrm{p} 75$, and RET. Most of the above markers of neural crest derived cells within the gut are downregulated during development. However, expression of Phox $2 b$ is maintained in adult mice and all differentiated enteric neurones show Phox $2 b$ immunoreactivity. Thus it would seem likely that Phox $2 b$ is expressed by all enteric neurone precursors. Double label studies revealed that Phox2b, p75, and RET are expressed by identical populations of neural crest derived cells in embryonic day 12-14 (E12-E14) mice, and it appears likely that these three molecules are expressed by all migratory, or immediate post-migratory, neural crest cells in the gut. We mapped the appearance of Phox 2b, p75, and RET immunoreactive cells in the embryonic mouse gut. ${ }^{19}$ At E9.5-E10, labelled cells were present only in the stomach, and during subsequent development Phox $2 b$, p75, and RET positive cells appeared as a unidirectional, rostral to caudal wave along the gastrointestinal tract; the entire gut was colo-

Abbreviations used in this paper: ENS, enteric nervous system; GDNF, glial derived neurotrophic factor. 


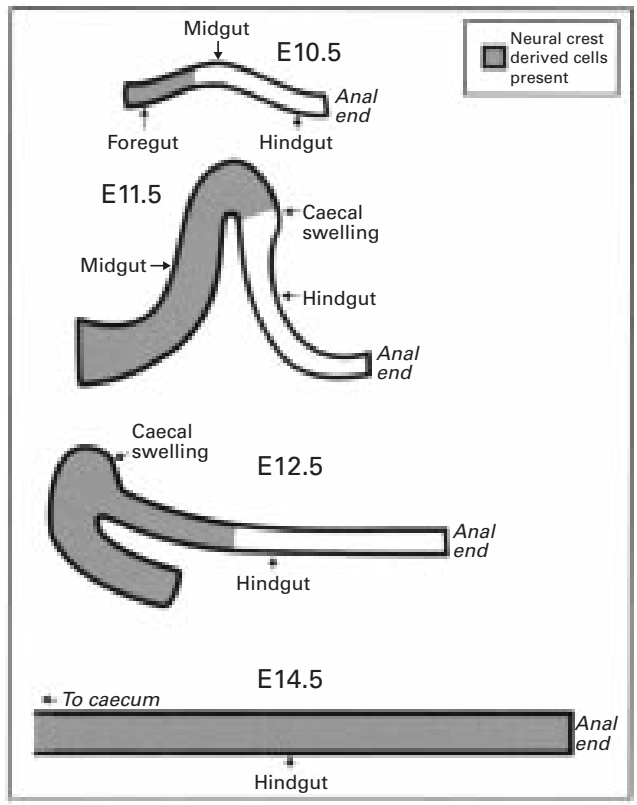

Figure 2 Colonisation of the gut by vagal level neural crest cells.

nised by E14 (fig 2). This wave of migrating cells represents colonisation of the gut by vagal level neural crest cells and is very similar to that described using the transgene $D B H-n l a c Z$ as a marker of neural crest derived cells. ${ }^{7}$ To confirm the location of enteric neurone precursors deduced from the use of Phox2b, RET, and p75 antisera, explants from spatiotemporally defined regions of embryonic mouse gut were removed and grown either under the kidney capsule of adult host mice $^{20}$ or in organ culture under conditions in which the gut retains its tubular three dimensional structure. ${ }^{21}$ The explants were grown for 1-3 weeks and examined for the presence of enteric neurones. The location and sequence of appearance of enteric neurone precursors deduced from the explants were very similar to those seen with Phox2b, RET, and p75 antisera. These results are difficult to reconcile with those of Serbedzija et al $(1991)^{6}$ who used DiI to label pre-migratory neural crest cells in embryonic mice, and reported that sacral neural crest cells leave the neural tube between E9 and E9.5 and arrive in the hindgut approximately 12 hours later. However, as the fate of DiI labelled cells could not be determined, it is possible that DiI labelled cells that migrated into the hindgut were not precursors of the ENS.

In our study, no Phox $2 b, \mathrm{p} 75$, or RET positive cells were observed in the hindgut of embryonic mice prior to the arrival of the vagal neural crest cells. ${ }^{19}$ However, from as early as E10, groups of labelled cells were observed outside of the hindgut in the primordium of the pelvic plexus. The pelvic plexus arises from the sacral neural crest, ${ }^{22}$ and thus sacral level neural crest cells that give rise to the pelvic plexus are labelled by the markers used in our study. However, Phox 2b, p75, and RET labelled sacral level neural crest cells did not appear to enter the hindgut either at all or until after the arrival of vagal level neural crest cells.
Recently, an important study was reported by Burns and Le Douarin $(1998)^{23}$ in which they repeated some of the experiments performed by Le Douarin and Teillet in the $1970 \mathrm{~s}^{2}$ where sacral level neural tubes of quail embryos were transplanted into chicken embryos in which the equivalent region of neural tube had been removed. They extended the original studies in two crucial ways. Firstly, they examined whether the sacral level neural crest cells (that is, quail cells) that entered the hindgut differentiated into neurones (rather than glia or some other cell type), and secondly, they examined when the sacral neural crest cells enter the hindgut. The sacral level neural crest cells that entered the hindgut were indeed found to differentiate into neurones. Thus there now appears to be no doubt that sacral level neural crest cells give rise to some enteric neurones in the hindgut of birds. The second important observation made in the study by Burns and Le Douarin ${ }^{23}$ was that the sacral level neural crest cells did not appear to enter the hindgut until around the time that the vagal level neural crest cells arrived. If sacral level neural crest cells do not enter the hindgut of embryonic mice until the vagal neural crest cells have colonised the hindgut, then we would not have been able to detect them with the techniques that we used. ${ }^{19}$ To examine whether cells within the pelvic plexus can give rise to enteric neurones in the hindgut of embryonic mice, we have recently removed segments of hindgut prior to the arrival of vagal neural crest cells and grown them in organ culture either alone or with attached dorsal tissue containing the pelvic plexus primordium. No neurones were observed in the explants of hindgut alone. However, the appearance of neurones in the explants of hindgut with attached pelvic plexus was variable. Some of the explants contained no neurones whereas other explants contained a small number of ganglia. Thus it appears that sacral level neural crest cells normally give rise to only a small number of enteric neurones in the hindgut of embryonic mice or they require the presence of vagal neural crest cells before significant migration into the hindgut or differentiation of sacral neural crest cells into neurones occurs.

\section{Development of different classes of enteric neurones}

During and following colonisation of the gut by neural crest cells, massive proliferation of neural crest cells occurs, followed by differentiation into glial cells or into one of the many different types of enteric neurones. Little is known of the factors that direct an individual neural crest cell along a glial or neuronal lineage, or along the lineages leading to different neuronal classes. Gene knockout studies have identified a number of molecules that are essential for the development of the ENS in particular regions of the gastrointestinal tract. For example, the transcription factor MASH1 is essential for the development of the ENS in the oesophagus; glial derived neurotrophic factor (GDNF) and its receptors RET and GFR $\alpha 1$ are essential for the development of the ENS in the gastro- 
MASH1

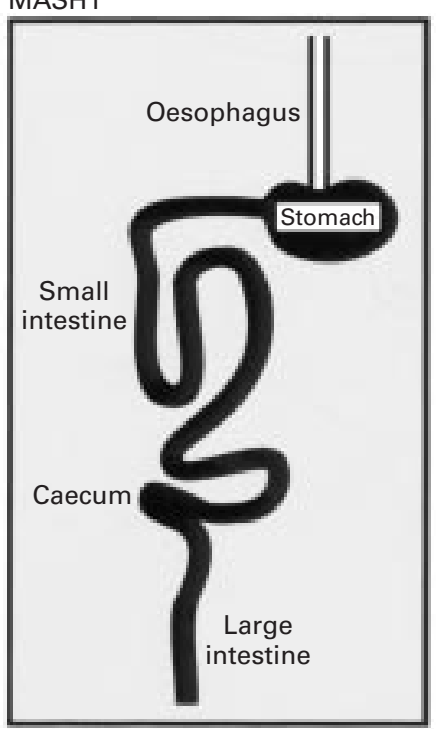

GDNF or RET or GFR $\alpha 1$

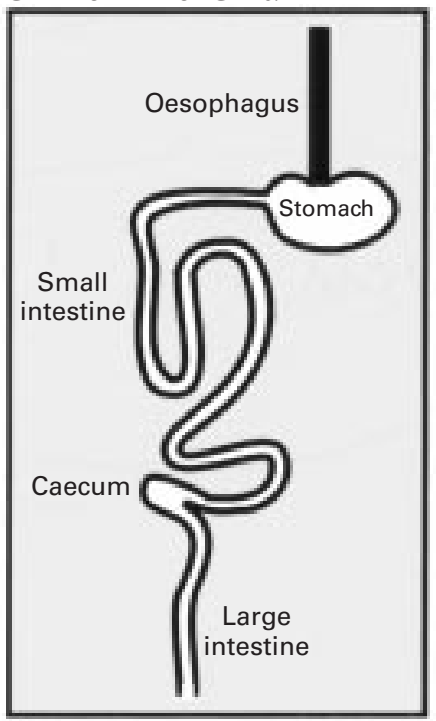

Endothelin 3 or EDNRB

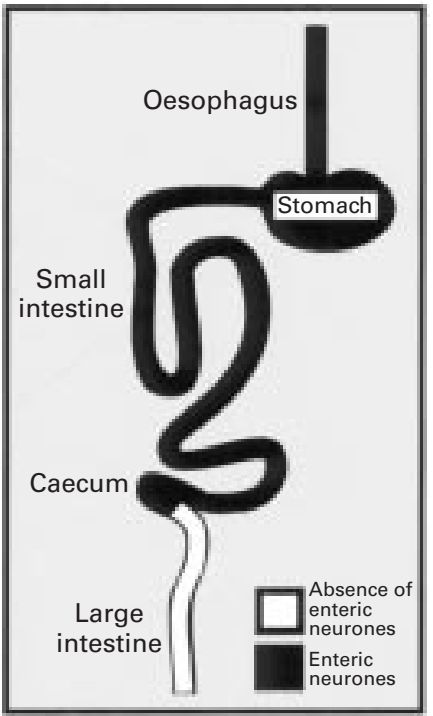

Figure 3 Use of gene knockout studies to identify molecules which are essential for the development of the enteric nervous system in different regions of the gut. GDNF, glial derived neurotrophic factor; GFRa 1, GDNF family receptor a1; EDNRB, endothelin $B$.

intestinal tract caudal to the stomach; and endothelin 3 and its receptor, endothelin receptor $\mathrm{B}$, are essential for the development of the ENS in the hindgut (fig 3) (for review see Gershon $^{24}$ ). However, in general, in any particular gut region, the absence of these molecules has an all or nothing effect on the development of the ENS, and thus MASH1, GDNF, and endothelin 3 appear to be involved in the very early development of the ENS, either in the migration of neural crest cells into the gut or in the survival, proliferation, or differentiation of neuronal precursors, rather than the development of particular classes of enteric neurones. Different classes of enteric neurones differentiate at different times, ${ }^{25}$ and as in other parts of the nervous system, there appear to be some phenotypic changes and aberrant projections during the development of some classes of enteric neurones. ${ }^{26}$

1 Yntema G, Hammond WS. The origin of intrinsic ganglia of trunk viscera from vagal neural crest in the chick embryo. $\mathcal{F}$ trunk viscera from vagal neural

2 Le Douarin NM, Teillet MA. The migration of neural crest cells to the wall of the digestive tract in avian embryo. $\mathcal{F}$ cells to the wall of the digestive tract
Embryol Exp Morphol 1973;30:31-48.

3 Allan IJ, Newgreen DF. The origin and differentiation of enteric neurons of the intestine of the fowl embryo. Am $\mathcal{F}$ Anat 1980;157:137-54

4 Meijers JH, Tibboel D, van der Kamp AW, et al. A model for aganglionosis in the chicken embryo. 7 Pediatr Surg 1989;24:557-61.

5 Pomeranz HD, Rothman TP, Gershon MD. Colonization of the post-umbilical bowel by cells derived from the sacral neural crest: direct tracing of cell migration using an intercalating probe and a replication-deficient retrovirus. Development 1991;111:647-55.

6 Serbedzija GN, Burgan S, Fraser SE, et al. Vital dye labelling demonstrates a sacral neural crest contribution to the enteric nervous system of chick and mouse embryos. Development 1991;111:857-66.

7 Kapur RP, Yost C, Palmiter RD. A transgenic model for studying development of the enteric nervous system in normal and aganglionic mice. Development 1992;116:167-75.

mal and aganglionic mice. Development 1992;116:167-75.
8 Bannerman PG, Pleasure D. Protein growth factor requirements of rat neural crest cells. F Neurosci Res 1993;36:4657.

9 Chalazonitis A, Rothman TP, Chen J, et al. Neurotrophin-3 induces neural crest-derived cells from fetal rat gut to develop in vitro as neurons or glia. $\mathcal{F}$ Neurosci $1994 ; 14$ 6571-84
10 Pachnis V, Mankoo B, Costantini F. Expression of the c-ret proto-oncogene during mouse embryogenesis. Development 1993;119:1005-17.

11 Jing S, Wen D, Yu Y, et al. GDNF-induced activation of the ret protein tyrosine kinase is mediated by GDNFR-alpha, a novel receptor for GDNF. Cell 1996;85:1113-24.

12 Treanor JJ, Goodman L, de Sauvage F, et al. Characterization of a multicomponent receptor for GDNF. Nature 1996;382:80-3.

13 Gariepy CE, Williams SC, Richardson JA, et al. Transgenic expression of the endothelin-B receptor prevents congeni$\mathrm{tal}$ intestinal aganglionosis in a rat model of Hirschsprung disease. F Clin Invest 1998;102:1092-101.

14 Lo LC, Johnson JE, Wuenschell CW, et al. Mammalian achaete-scute homolog 1 is transiently expressed by spatially restricted subsets of early neuroepithelial and neural crest cells. Genes Dev 1991;5:1524-37.

15 Tiveron MC, Hirsch MR, Brunet JF. The expression pattern of the transcription factor Phox 2 delineates synaptic pathways of the autonomic nervous system. I Neurosci 1996;16:7649-60.

16 Pattyn A, Morin X, Cremer H, et al. Expression and interactions of the two closely related homeobox genes Phox2a and Phox2b during neurogenesis. Development 1997;124: 4065-75.

17 Herbarth B, Pingault V, Bondurand N, et al. Mutation of the Sry-related Sox10 gene in dominant megacolon, a mouse Sry-related Sox10 gene in dominant megacolon, a mouse USA 1998;95:5161-5.

18 Southard-Smith EM, Kos L, Pavan WJ. Sox10 mutation disrupts neural crest development in Dom Hirschsprung mouse model. Nat Genet 1998;18:60-4.

19 Young HM, Hearn CJ, Ciampoli D, et al. A single rostrocaudal colonization of the rodent intestine by enteric neuron precursors is revealed by the expression of Phox $2 b$, Ret, and p75 and by explants grown under the kidney capsule or in organ culture. Dev Biol 1999;202:67-84.

20 Young HM, Ciampoli D, Southwell BR, et al. Origin of interstitial cells of Cajal in the mouse intestine. Dev Biol 1996;180:97-107.

21 Hearn CJ, Young HM, Ciampoli D, et al. Catenary cultures of embryonic gastrointestinal tract support organ morphogenesis, motility, neural crest cell migration, and cell differentiation. Dev Dyn 1999;214:239-47.

22 Yntema GL, Hammond WS. Experiments on the origin and development of the sacral autonomic nerves in the chick embryo. f Exp Zool 1955;129:375-413.

23 Burns AJ, Douarin NM. The sacral neural crest contributes neurons and glia to the post-umbilical gut: spatiotemporal analysis of the development of the enteric nervous system. Development 1998;125:4335-47.

24 Gershon MD. Genes and lineages in the formation of the enteric nervous system. Curr Opin Neurobiol 1997;7:101-9.

25 Branchek TA, Gershon MD. Time course of expression of neuropeptide Y, calcitonin gene-related peptide, and NADPH diaphorase activity in neurons of the developing murine bowel and the appearance of 5-hydroxytryptamine in mucosal enterochromaffin cells. f Comp Neurol 1989; in mucosal

26 Young HM, Ciampoli D. Transient expression of neuronal nitric oxide synthase by neurons of the submucous plexus of the mouse small intestin. Cell Tissue Res 1998;291:395-401. 